\section{AB0278 INVESTIGATION OF POOR PROGNOSTIC FACTORS AMONG RHEUMATOID ARTHRITIS PATIENTS IN TURKBIO REGISTRY}

N. Inanc ${ }^{1}$, Z. Ertürk' ${ }^{1}$, G. Ozen ${ }^{1}$, E. Dalkilıç ${ }^{2}$, S.S. Koca ${ }^{3}$, G. Can ${ }^{4}$, A. Karatas ${ }^{3}$, Y. Pehlivan ${ }^{2}$, A. Yazici ${ }^{5}$, A. Cefle 5 , S. Akar ${ }^{6}$, S. Senel', B. Oz ${ }^{3}$, N. Akkoc $^{8}$,

H. Direskeneli'. 'Rheumatology, Marmara University School of Medicine, Istanbul;

${ }^{2}$ Rheumatology, Uludag University School of Medicine, Bursa; ${ }^{3}$ Rheumatology,

Firat University School of Medicine, Elazığ; ${ }^{4}$ Rheumatology, Dokuz Eylül University School of Medicine, Izmir, ${ }^{5}$ Rheumatology, Kocaeli University School of Medicine, Kocaeli; ${ }^{6}$ Rheumatology, Izmir Katip Çelebi University School of Medicine, Izmir, ${ }^{7}$ Rheumatology, Erciyes University School of Medicine, Kayseri, ${ }^{8}$ Rheumatology, Private Practice, Izmir, Turkey

Background: TURKBIO is the Turkish version of Danish DANBIO rheumatologic database which has been established in 2011. Patients' data including age, sex, disease type and duration, and previous or current treatment with conventional (cs), targeted synthetic (ts) and biological (b) DMARDs were collected. In 2016, the EULAR RA management guideline recommended assessment of certain prognostic factors while deciding the treatment strategy after the first cSDMARD failure.

Objectives: We examined the frequency and influence of these poor prognostic factors on treatment response in $\mathrm{DDMARD}$ and tsDMARD initiating RA patients enrolled in TURKBIO.

Methods: 898 biological and targeted synteticDMARDs receiving RApatients from 8 participating centres ofTURKBIO werestudied. Seven investigated poorprognostic factors were: ${ }^{1}$ Moderate to high disease activity (aftercsDMARD therapy), ${ }^{2}$ Elevated acute phase reactants, ${ }^{3}$ High swollen joint counts $(>4),{ }^{4}$ High RF/ ACPA titers, ${ }^{5}$ Combinations of the above, ${ }^{6}$ Erosions, ${ }^{7}$ Failure of $\geq 2$ csDMARDs. The frequencies of these factors at treatment initiation and influence of these on achievement of remission/remission+low disease activity (LDA) according to DAS28-CRP at the 6th month of treatment were evaluated in overall any bDMARD and tsDMARD-receiving patients.

Results: Among the prognostic factors; factors 1, 2, 4, 6 and 7 were found in over $60 \%$ of patients while factors 3 and 5 were present in about $30 \%$. Factors 1 and 3 were more frequent in patients who were in moderate/high disease activity compared to those in remission +low disease activity (table 1). Same factors 1 and 3 were determined at higher percentage in non-remission than remission group (Factor $1: 93.4 \%$ vs. $82.2 \%, p<0.001$; factor $3: 43 \%$ vs. $30.7 \%$, $p=0.002$ ). These two factors were also significantly more frequent in patients withdrawn from the treatment (Factor $1: 93 \%$ vs. $85 \%, p<0.001$; factor $3: 41 \%$ vs. $34 \%, p=0.038$ ). In TNFi group besides factors 1 and 3 , factors 5 and 7 were also significantly more frequent in non-remission group whereas, in the RTX group, only factor 1 was significantly more frequent in remission group. For the other bDMARDs and tsDMARD (ABA, TCZ, TOFA), we did not find any difference in poor prognostic factors among patients who did achieve remission and did not.

Abstract AB0278 - Table 1. Frequencies of poor prognostic factors in RA patients initiating bDMARDs and tsDMARD by disease activity ${ }^{*}$ at the 6 th month of treatment

\begin{tabular}{|c|c|c|c|}
\hline Factors & $\begin{array}{l}\text { Remission+low } \\
\text { disease activity, \% }\end{array}$ & $\begin{array}{l}\text { Moderate+high } \\
\text { disease activity, \% }\end{array}$ & P value \\
\hline $\begin{array}{l}\text { Factor 1: Moderate to high disease } \\
\text { activity (after csDMARD therapy) }\end{array}$ & 95.9 & 83.6 & $<0.001$ \\
\hline $\begin{array}{l}\text { Factor 2: Elevated acute phase } \\
\text { reactants }\end{array}$ & 100 & 99.5 & : \\
\hline $\begin{array}{l}\text { Factor 3: High swollen joint counts } \\
\text { (34) }\end{array}$ & 47.1 & 31.7 & $<0.001$ \\
\hline Factor $4:$ High RF/ACPA titers & 68.3 & 71.9 & 0.465 \\
\hline $\begin{array}{l}\text { Factor } 5 \text { : Combinations of the factors } \\
1,2,3,4\end{array}$ & 31.3 & 25.9 & 0.284 \\
\hline Factor 6: Erosions & 56.5 & 65.6 & 0.332 \\
\hline Factor $7:$ Failure of $\geq 2$ csDMARDs & 69.4 & 69 & 0.918 \\
\hline
\end{tabular}

Conclusions: Five of the seven poor prognostic factors were detected more than half of the RA patients at bDMARD and tsDMARD initiation in TURKBIO. Patients with poor prognostic factors especially factors 1 and 3 achieved remission less frequently. Additionally, there was a relationship between bDMARDs and tsDMARD withdrawal and factors 1 and 3 . The influence of these factors was mainly observed in TNFi receiving group.

Disclosure of Interest: None declared

DOI: 10.1136/annrheumdis-2018-eular.4259

\section{AB0279 \\ RAPID3 IS NOT LONGITUDINALLY ASSOCIATED WITH DAS28-ESR IN PATIENTS WITH RHEUMATOID ARTHRITIS}

N. Boone ${ }^{1}$, A. Sepriano ${ }^{2,3}$, R. Janknegt ${ }^{1}$, H. van der Kuy ${ }^{4}$, R. Peeters ${ }^{5,6}$, R. Landewé ${ }^{5}{ }^{1}$ Department of Clinical Pharmacology and Toxicology, Zuyderland Medical Centre, Sittard-Geleen; ${ }^{2}$ Department of Rheumatology, Leiden University Medical Centre, Leiden, Netherlands; ${ }^{3}$ Nova Medical School, Universidade Nova de Lisboa, Lisboa, Portugal; ${ }^{4}$ Department of Clinical Pharmacy, Erasmus Medical Centre, Rotterdam; ${ }^{5}$ Department of Rheumatology, Zuyderland Medical Centre, Sittard-Geleen Heerlen; ${ }^{6}$ Amsterdam Rheumatology and Immunology Centre, Amsterdam, Netherlands

Background: The Routine Assessment of Patient Index Data 3 (RAPID3) is a patient reported outcome (PRO) proposed to conveniently measure disease activity in rheumatoid arthritis (RA) based on functioning, pain and global health scores. DAS28 (including PRO and objective measures) is the most frequently used score in clinical practice and research for that purpose ${ }^{[1]}$. It has been suggested that composite scores measuring PROs only (e.g. RAPID3) might add to the assessment of disease activity over time but this claim is yet to be formally tested.

Objectives: In this study we evaluated a possible longitudinal association between RAPID3 and DAS28-ESR (including individual components) in patients with $R A$ from daily clinical practice.

Methods: Adult patients with RA on stable treatment with either conventional synthetic disease modifying drugs (csDMARDs) and/or biologic DMARDs (bDMARDs), followed in one centre, were included. Patients were followed every 3 months up to 3 years and in each visit both clinical and medication data was collected by rheumatologists/research nurses. The longitudinal association between RAPID3 (range: 0-30) with DAS28-ESR and its individual components [tender joint count (TJC; 0-28); swollen joint count (SJC; 0-28); patient global assessment $(\mathrm{PGA} ; 0-10)$ and $\mathrm{ESR}(\mathrm{mm} / \mathrm{h})]$ was tested (in separate models) by longitudinal generalised estimating equations (GEE) with auto-regression. Interactions between RAPID3 with gender (male vs female), VAS pain $(\geq 5$ vs $<5)$, PGA $(\geq 5$ vs $<5$ ) and age ( $\geq 62$ vs $<62$ ) at baseline were tested and if significant $(p<0.20)$ and clinically relevant each model (either using DAS28 or its individual components as outcome) was stratified accordingly.

Results: In total, 330 patients were included [mean (SD) age: $62^{12}$ years, $68 \%$ female, baseline mean (SD) DAS28: 3.3 (1.4) and RAPID3: 11.5 (6)]. The mean (SD) follow-up period was 10.7 (9.7) months. Although, statistically significant, we only found a poor association between RAPID3 and DAS28-ESR over time (table 1). An increase of one unit in RAPID3 (0-30) was associated with an increase of only 0.1 units of DAS28-ESR. Gender, age, PGA and VAS pain were not found to meaningfully modify the association between RAPID3 and DAS28. A far stronger association was found between RAPID3 and the 'subjective components' [TJC: $\beta=0.30$ (95\%: $0.20 ; 0.39)$; and PGA: $\beta=0.31$ (95\%: $0.28 ; 0.35)$ ] of DAS28-ESR, as compared to the 'objective components' (i.e., SJC and ESR; the latter only significant in males) (table 1).

Abstract AB0279 - Table 1. Longitudinal association between RAPID3 and DAS28 and each individual component

\begin{tabular}{lccc}
\hline & Main effect & Males & Females \\
& $\beta(95 \% \mathrm{Cl})$ & $\beta(95 \% \mathrm{Cl})$ & $\mathrm{N}(95 \% \mathrm{Cl})$ \\
\hline DAS28 ESR & $0.10(0.10 ; 0.10)$ & $\mathrm{NA}$ & $\mathrm{NA}$ \\
Swollen joint count & $0.10(0.06 ; 0.14)$ & $\mathrm{NA}$ & $\mathrm{NA}$ \\
ESR & $\mathrm{NA}$ & $0.12(0.03 ; 0.22)$ & $-0.10(-0.16 ; 0.14)$ \\
Tender joint count & $0.30(0.20 ; 0.39)$ & $\mathrm{NA}$ & $\mathrm{NA}$ \\
PGA & $0.31(0.28 ; 0.35)$ & $\mathrm{NA}$ & $\mathrm{NA}$ \\
\hline
\end{tabular}

Each line is a separate model; NA, not applicable.

Conclusions: There is no meaningful longitudinal association between RAPID3 and DAS28. DAS28 captures objective signs of disease activity over time in RA while RAPID3 only captures subjective symptoms of RA.

\section{REFERENCE:}

[1] Van der Heijde DM, et al. Development of a disease activity score based on judgment in clinical practice by rheumatologists. J Rheumatol 1993.20:579-581.

Disclosure of Interest: None declared DOI: 10.1136/annrheumdis-2018-eular.6910 